\title{
Environmental factors and public health policy associated with human and rodent infection by leptospirosis: a land cover-based study in Nan province, Thailand
}

\author{
P. DELLA ROSSA ${ }^{1}$, K. TANTRAKARNAPA ${ }^{2}$, D. SUTDAN ${ }^{3}$, \\ K. KASETSINSOMBAT ${ }^{4}$, J.-F. COSSON $^{5}$, Y. SUPPUTAMONGKOL ${ }^{6}$,

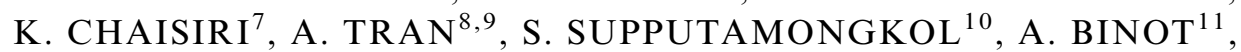 \\ C. LAJAUNIE ${ }^{12}$ AND S. MORAND ${ }^{7,13 *}$
}

${ }^{1}$ Institut des Sciences de l'Evolution, CNRS-IRD-UM2, Université de Montpellier 2, Montpellier, France;

${ }^{2}$ Department of Epidemiology and Public Health, Faculty of Tropical Medicine, Mahidol University, Ratchathevi, Bangkok, Thailand; ${ }^{3}$ District Hospital of Tha Wang Pha, Tha Wang Pha, Nan province, Thailand; ${ }^{4}$ District hospital of Pua, Pua, Nan province, Thailand; ${ }^{5}$ INRA, UMR CBGP (INRA/IRD/CiradlMontpellier SupAgro), Campus International de Baillarguet, Montferrier-sur-Lez Cedex, France; ${ }^{6}$ Faculty of Medecine, Siriraj Hospital, Bangkok, Thailand; ${ }^{7}$ Department of Helminthology, Faculty of Tropical Medicine, Mahidol University, Ratchathevi, Bangkok, Thailand; ${ }^{8}$ CIRAD, UMR TETIS, Montpellier, France; ${ }^{9}$ UR22 AGIRs, Centre de coopération Internationale en Recherche Agronomique pour le Développement (CIRAD), Campus International de Baillarguet, Montpellier, France; ${ }^{10}$ Department of Anthropology, Thammasat University, Bangkok, Thailand; ${ }^{11}$ CIRAD AGIRs, Faculty of Veterinary Medicine, Kasetsart University, Bangkok, Thailand; ${ }^{12}$ INSERM U095, URMITE-UMR CNRS 7278, University of Aix-Marseille, Marseille, France; ${ }^{13}$ CNRS-CIRAD AGIRs, Centre d'Infectiologie Christophe Mérieux du Laos, Vientiane, Lao PDR

Received 19 June 2015; Final revision 21 September 2015; Accepted 27 October 2015; first published online 26 November 2015

\section{SUMMARY}

Leptospirosis incidence has increased markedly since 1995 in Thailand, with the eastern and northern parts being the most affected regions, particularly during flooding events. Here, we attempt to overview the evolution of human prevalence during the past decade and identify the environmental factors that correlate with the incidence of leptospirosis and the clinical incidence in humans. We used an extensive survey of Leptospira infection in rodents conducted in 2008 and 2009 and the human incidence of the disease from 2003 to 2012 in 168 villages of two districts of Nan province in Northern Thailand. Using an ad-hoc developed land-use cover implemented in a geographical information system we showed that humans and rodents were not infected in the same environment/ habitat in the land-use cover. High village prevalence was observed in open habitat near rivers for the whole decade, or in 2008-2009 mostly in rice fields prone to flooding, whereas infected rodents (2008-2009) were observed in patchy habitat with high forest cover, mostly situated on sloping ground areas. We also investigated the potential effects of public health campaigns conducted after the dramatic flood event of 2006. We showed that, before 2006, human incidence in villages was explained by the population size of the village according to the environmental source of infection of this disease, while as a result of the campaigns, human incidence in villages after 2006 appeared independent of their population size. This study confirms the role of the environment and particularly land use, in the transmission of bacteria, emphasized by the effects of the provincial public health campaigns on the epidemiological pattern of incidence, and questions the role of rodents as reservoirs.

Key words: Geographical information systems, leptospirosis, public health, rodents, zoonotic foodborne diseases.

\footnotetext{
* Author for correspondence: S. Morand, CNRS-CIRAD, Centre d'Infectiologie Christophe Mérieux du Laos, Vientiane, Lao PDR. (Email: serge.morand@univ-montp2.fr)
} 


\section{INTRODUCTION}

Leptospirosis is a re-emerging disease caused by pathogenic spirochetes of the genus Leptospira [1-3], of which rodents are believed to be important carriers [4-6]. According to the World Health Organization the global burden of leptospirosis is estimated at over one million severe human cases per year, with a growing number of countries reporting leptospirosis outbreaks $[3,7]$. Leptospirosis can represent up to $20-40 \%$ of idiopathic febrile illness [8]. South-East Asia is a region of particularly high incidence with Thailand, Cambodia, Laos, Philippines and Vietnam considered as areas in which leptospirosis is endemic $[5,9,10]$. The disease shows seasonal peaks of incidence during the rainy season in this tropical region, where most outbreaks seem to be related to flooding events [11-13].

Human infection is related to normal daily activities associated with poor sanitation and climatic conditions [14]. Exposure to pathogenic leptospires occurs by direct contact with urine of infected animal reservoirs, or indirectly with water contaminated by urine of infected animals. Generally, these animals are rodents, but also include dogs or livestock, in which leptospires can persist without clinical signs [15]. Rodents are repeatedly cited as the main reservoirs [5, 6, 16-20]. However, pathogenic bacteria can survive in water long enough (from a few days to several months) to become the source of human or animal contamination [21]. For instance, Ganoza et al. [22] showed that the concentration and species of leptospires found in environmental surface water correlated with the risk of severe leptospirosis in humans.

In Thailand, the disease was recorded for the first time in 1942 [23]. While leptospirosis incidence remained low until the 1990s, the number of cases increased markedly in 1995 with 143 cases reported, and continued to increase to a peak of 14285 reported cases in 2000 [23]. Seasonal peak incidence occurs in the wet season, from September to October, 1 month after the rainfall peak. The eastern and northern parts of Thailand are the most affected regions [24].

In order to better understand leptospirosis infection, this study attempted to overview the evolution of human infection over the past decade with regard to the influence of the public health campaign introduced by the Thai government in 2006, and identify the environmental factors that correlate with the incidence of bacteria in rodents and the clinical incidence in humans. Hence, in 2006, heavy flooding in Nan province led the provincial authorities to greatly improve health prevention by conducting regular awareness campaigns (encouraging farmers to wear boots and controlling rodent populations) and prophylaxis by allowing large distribution of antibiotics during flooding events. We then investigated the potential effects of these campaigns on the relationships between environmental factors and leptospirosis incidence, by comparing the periods before and after 2006. We hypothesized that, before 2006, human incidence should be mainly explained by the population size of the villages according to the environmental source of infection of this disease, whereas due to the campaigns conducted after 2006, human incidence in villages should be independent of their population size.

By investigating the environmental factors that correlate with rodent infection, we also tested the role of rodents in leptospire transmission to humans. We hypothesized that if rodents are a potential source of leptospire infection to humans, a co-occurrence of infection in rodents and humans should be observed in the same environment (i.e. habitat in land use). By using a rodent screening survey, we were able to test this hypothesis for the period 2008-2009.

Our approach is at the interface between health geography and spatial epidemiology. For this, we used an extensive survey of Leptospira infection in rodents conducted in 2008 and 2009 together with the human incidence of the disease from 2003 to 2012 in two districts of Nan province, Thailand and a land-use cover implemented in a Geographic Information System [25, 26].

\section{MATERIALS AND METHODS}

\section{Ethical statement}

Systematic field sampling was performed by joint Thai and French research institute teams. Traps were set within houses with the oral approval of the owner or tenant. Outdoors, traps were set with the agreement of the head of the village. None of the rodent species investigated are on the CITES list, nor the Red List (IUCN). Animals were treated in accordance with the guidelines of the American Society of Mammalogists, and European Union legislation (Directive 86/609/EEC). Each trapping campaign was approved by the national, regional and local health authorities. Human incidence cases were 
gathered by the district hospitals of Tha Wang Pha and Pua. Approval notices for trapping and investigation of rodents, and use of human incidence recordings were given by the Ethics Committee of Mahidol University, Bangkok, Thailand (no. 0517.1116/661).

\section{Study location}

Nan province is located in northern Thailand where prevalence of leptospirosis is high compared to other regions of the country [24]. In this rural area, farmers are thought to be exposed to leptospirosis in rice fields with standing water. In 2006, Nan was affected by a flood event and 1400 cases were reported after the peak of the flooding. Following this event, the government decided to introduce a prevention campaign by encouraging farmers to wear boots and by controlling rodent populations. Because of the high prevalence there and the government's major concern regarding leptospirosis emergence, Nan represents an important location to study both the impacts of environmental factors and the efficiency of health prevention policy.

We restricted the screening of leptospires to rodents, although domesticated animals have been mentioned to be involved as reservoirs of leptospires. However, the two districts investigated showed low abundance of water buffaloes and cattle due to agricultural intensification both in mechanization and cropping, especially corn, that reduced the presence of cattle herds. Dogs were also believed to be reservoirs, but as they live mainly in settlements (i.e. South-East Asian village dogs) they were not considered as main reservoirs for the whole habitats such as forests and agricultural lands [27].

We used the data published on rodents in the two districts in 2008-2009 concerning 94 individual rodents [6], which were obtained by a screening of 131 individual rodents trapped at the same period. We summarize below the methods used for rodent sampling, rodent identification and Leptospira identification, which were extensively developed in previous published studies [6].

\section{Rodent sampling}

Rodents were trapped in Nan province, Thailand $(19.15 \mathrm{~N}, 100.83 \mathrm{E})$ in 2008 and 2009, within the framework of the CERoPath project (www.ceropath. org). Thirty lines of 10 traps were placed during four nights in three different habitats: (1) forests and mature plantations; (2) non-flooded lands or fields (shrubby wastelands, young plantations, orchards), (3) rain-fed lowland paddy rice fields (cultivated floodplain) (according to [28]). Villages and isolated houses, which correspond to a fourth habitat category (4), namely the human settlement, were sampled using cage-traps distributed to residents. We used locally made cage live-traps (about $40 \times 12 \times 12 \mathrm{~cm}$ ). We sampled twice: once in the wet season and once in the dry season with 1200 night-traps per trapping session (2400 in total). In both seasons, trap lines were located at the same place (using a Global Positioning System receiver). (For more detailed description of the trapping protocols see $[26,29]$.)

\section{Rodent identification}

Rodent species were identified in the field using morphological criteria (see www.ceropath.org/references/ rodent_field_guide). When morphological criteria did not allow distinguishing species of some genera, molecular techniques were also used. We used a mitochondrial gene for barcoding Mus species and some Rattus species [30]. Voucher specimens (skulls) are deposited at the Institut des Sciences de l'Evolution (Montpellier, France), rodent tissues (liver preserved in alcohol) are deposited at the Kasetsart University (Department of Veterinary Medicine, Bangkok, Thailand).

\section{Leptospira infection in rodents}

The screening of leptospires was performed on rodent kidneys. Real-time polymerase chain reaction (RTPCR) targeting lipL32 and $\beta$-actin genes was performed on rodent kidney DNA, extracted with a Bio Basic EZ-10 96 Well Plate genomic DNA isolation kit and the Qiagen DNeasy ${ }^{\circledR}$ Blood \& Tissue kit (Qiagen S.A.S., France). Following alignment of $\beta$-actin gene sequences of Asian rodents, $\beta$-actin primers (forward: 5'-CCA TGA AAC TAC ATT CAA TTC CA-3'; reverse: 5'-TTC TGC ATC CTG TCA GCA A-3') and probe (5'-AGA CCT CTA TGC CAA CAC AGT GCT G-3') were designed using the highly conserved fifth exon sequence along with the Probe Design software for Light Cycler LC480 (Roche, USA). $\beta$-actin was used as an internal control for RT-PCR. In order to identify the human pathogenic strains, the TaqMan lipL32 assay, which targets a gene encoding for a pathogen-specific outer membrane protein in Leptospira, was performed using primers (forward: 5'-AAG CAT TAC CGC TTG TGG 
TG-3'; reverse: 5'-GAA CTC CCA TTT CAG CGA TT-3') and probe (5'-AAA GCC AGG ACA AGC GCC G-3'). The amplification was performed on a Light Cycler 480 thermocycler (Roche). A $\mathrm{C}_{\mathrm{t}}<40$ for the lipL32 amplicons was considered positive for Leptospira. (For more detailed information see [6].)

Conventional PCR assays targeting the rrs gene were performed on positive RT-PCR samples. All samples were also amplified for $\sec Y$. The $r r s$ and sec $Y$ PCR products were sequenced at the Platform Genotyping of Pathogens and Public Health (Institut Pasteur, Paris, France). Leptospira species were identified by sequencing $r r s$ genes and subsequent BLAST searches using the GenBank database. (For more detailed information see [6].)

\section{Land cover and environmental indices}

Recent (2007-2008) high spatial resolution $(2.5 \mathrm{~m}$ in panchromatic mode and $10 \mathrm{~m}$ in multispectral mode) SPOT 5 satellite images were acquired (CNES 2009, distributed by Astrium Services/Spot Image S.A., France). SPOT-Digital Elevation Model (DEM) with a spatial resolution of $20 \mathrm{~m}$ together with the SRTM (Shuttle Radar Topography Mission, http:// srtm.usgs.gov/) DEM (90-m spatial resolution) were also acquired, allowing estimations of elevation and slope. The SPOT scene was classified into different land-cover types using an object-based approach (eCognition Developer software) [25]. Each scene was first segmented into objects, which were then classified using a supervised process based on three types of object properties: intrinsic characteristics (reflectance values, slope values, shape and texture), topological characteristics (relationships to neighbouring objects) and contextual characteristics (semantic relationships between objects). The schemes were merged into five main classes: forest, steep agricultural land (i.e. non-flooded agriculture), flat agricultural land (i.e. flooded, irrigated, paddy fields), water surface (ponds, lakes, rivers), and built-up surfaces (i.e. villages, cities). The land-cover map and the DEM were integrated into a Geographic Information System (GIS) in ArcGIS 10.0 software (ESRI, USA). Landscape metrics to assess actual fragmentation were extracted from the land-cover classifications using the Fragstats freeware (www. umass.edu/landeco/research/fragstats/fragstats.html) and included proportions of each land-cover type, patch density (i.e. density of the different land-cover types), and border density (i.e. density of the contour of all patches) [25]. (See more detailed information in [26].)

\section{Human incidence}

Data on leptospirosis incidence were obtained for each of 168 villages, for the years 2003-2012, from the district hospitals of Tha Wan Pha and Pua. Patients were clinically diagnosed in district hospitals, and only patients with severe symptoms were laboratoryconfirmed for leptospirosis. The GPS localizations of villages were obtained in the field with the help of the Department of Agriculture Extension of both districts of Tha Wan Pha and Pua (Fig. 1). Sixty percent of villages have $<35 \%$ of forest area $2 \mathrm{~km}$ around the village. Data on human incidence in both villages are given in Figure 2.

\section{Statistical analyses}

To analyse the infection of rodents, we modelled the probability of presence/absence of the Leptospira infection as a function of several environmental indices with a logistic regression [Generalized Linear Model (GLM) with logit function] using package lme4 implemented in R [31]. Cases in each logistic regression were infected or non-infected individual rodents. A first initial model (rodent model 1) included the explanatory variables related to distance between the place where each individual rodent were trapped and the main habitats: distance from forest (Dist Forest), distance from human settlement (Dist Settl), distance from agriculture on steep land (Dist Agri steep), distance from agriculture on flat land (Dist Agri flat). The second initial model (rodent model 2) included the environmental indices related to the habitat structure, and was calculated for a buffer of $100 \mathrm{~m}$ for each individual rodent trapped: cover of agriculture on steep land (\%Agri steep), cover of agriculture on flat land (\%Agri flat), cover of forest (\%Forest), cover of human settlement (\%Settl) and patch density. No interactions were added to the independent variables. Selection of the best model was done using a stepforward procedure based on Akaike's Information Criterion (AIC) for both initial models.

To analyse the leptospirosis incidence in humans, we modelled the number of leptospirosis infection by village as a function of population size and several environmental indices with a GLM with a negative binomial distribution using package lme4 implemented in $\mathrm{R}$. The environmental indices related to the distance 


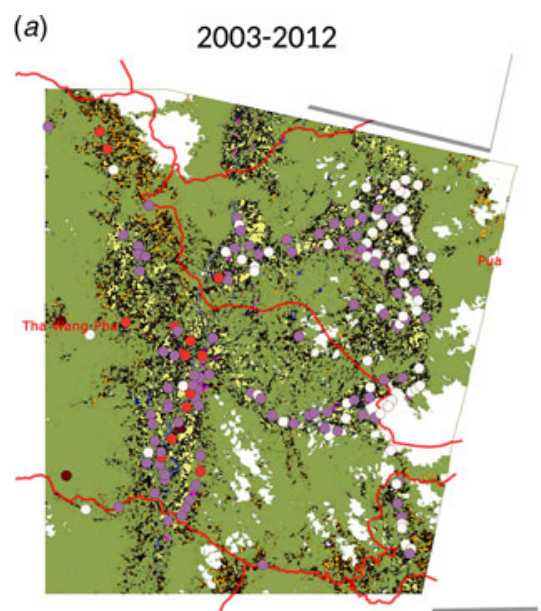

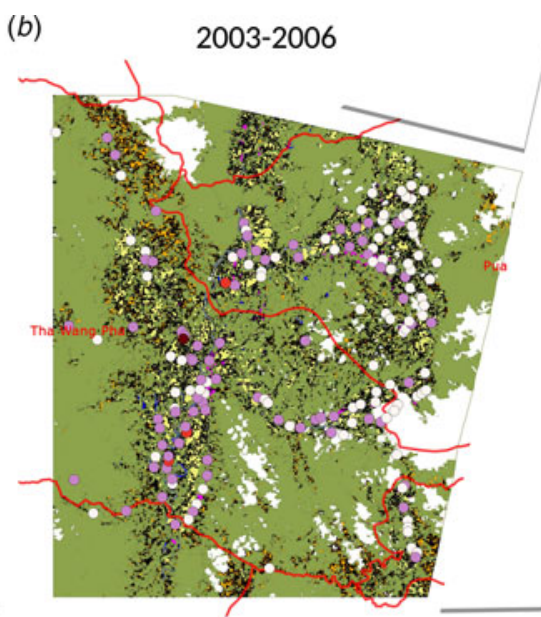

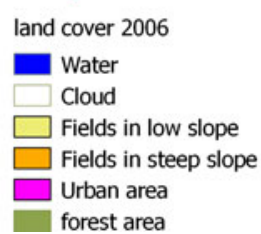

(c) 2007-2012

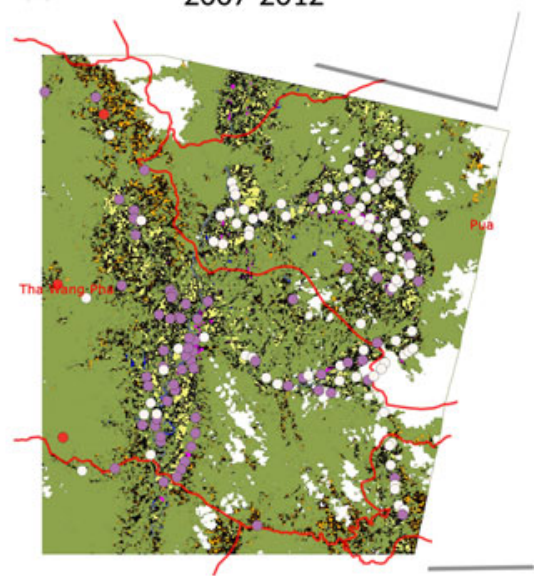

Human cases per village

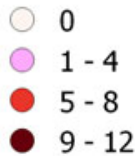

Fig. 1. Simplified land use of Tha Wang Pha and Pua districts showing the villages with number of leptospirosis cases. $(a)$ 2003-2012, (b) 2003-2006, (c) 2007-2012.

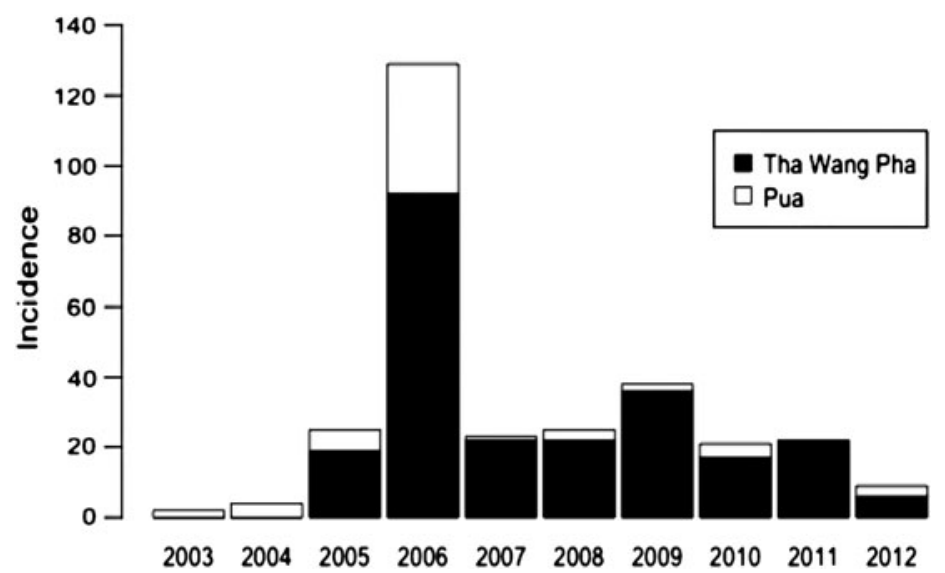

Fig. 2. Values of leptospirosis incidence in the two districts of Tha Wang Pha and Pua from 2003 to 2012.

to water source (river), altitude and the habitat structure calculated for a buffer of $4 \mathrm{~km}$ diameter for each village (corresponding roughly to the agricultural lands of the villages): cover of agriculture on steep land (\%Agri steep), cover of agriculture on flat land (\%Agri flat), cover of forest (\%Forest), cover of human settlement (\%Settl), patch density,

We analysed the total number of incidence cases from 2003 to 2012 (human model 1), and separately the period 2003-2006 (human model 2) and the period 2007-2012 (human model 3) in order to test the effect of the public health policy of the Nan provincial administration, characterized by an improvement of prevention and campaign for leptospirosis infection and the provision of antibiotics as prophylaxis during flooding events. We analysed the period (2008-2009) (human model 4) in order to compare leptospirosis infection in humans and rodents. We tested the existence of potential spatial autocorrelation using the package mass implemented in $\mathrm{R}$.

\section{RESULTS}

\section{Rodent infection}

The 225 individual trapped rodents from eight species were tested by PCR for infection by Leptospira 
(merged with the data published in [6]). The percentage of trapping success is low, $<5 \%$, with more 5000 night-traps including lines and traps given to local people. Of these, $10(4 \cdot 4 \%)$ were found to be infected by Leptospira interrogans (Table 1). Bandicota indica was the most infected rodent, although the bacteria were found in Berylmys berdmorei, Berylmys bowersi and Rattus tanezumi.

The best GLMs with logit function showed the importance of several environmental indices in explaining the presence of Leptospira in rodents (Table 1). An infection was likely observed in relation to forest habitat and human settlement (Table 2). Increase in habitat fragmentation, together with large patches of forest, appears to be positively associated with rodent infection (Table 3, Fig. 3).

\section{Human incidence}

The evolution of human incidence in Tha Wang Pha and Pua districts shows that before 2006 incidence was low. In 2006 we observed a sudden increase in incidence, related to flooding events in this area (Fig. 2). After 2006 and the beginning of a new public health policy, incidence became low again, but still higher than before. The best GLMs with negative binomial function showed that, for all years 2003-2012 (human model 1), villages with high leptospirosis incidence were situated close to a river in a non-patchy habitat, dominated by agricultural land on steep slopes, at low altitude (Tables 4 and 5). Population size was also a significant factor explaining human incidence. These results are visualized using partial contribution of village population size, partial contribution of distance to the river and partial contribution of patch density to human cases (Fig. $4 a-c$ ). High human incidence was better related to a lower distance to the river than a lower habitat fragmentation (patch density).

Separating the analyses before (human model 2) and after (human model 3) 2006 showed contrasting results (Tables 4 and 5). Human model 2 was similr to human model 1 , with the influences of distance to river, altitude, population and agricultural land on steep slopes explaining human incidence (Tables 4 and 5). Partial contribution of distance to the river to human cases followed the same trend (Fig. 4). Human model 3 differed from human models 1 and 2 by showing the importance of forest cover in the vicinity of villages leading to high incidence of cases. Partial contribution of distance to the river and forest
Table 1. Rodent species trapped and tested for Leptopsira infection in Tha Wang Pha and Pua districts of Nan province (Northern Thailand)

\begin{tabular}{lrl}
\hline \hline Rodent species & No. tested & Leptospira positive $(\%)$ \\
\hline Bandicota indica & 65 & $7(10 \cdot 7)$ \\
Berylmys berdmorei & 10 & $1(10 \cdot 0)$ \\
Berylmys bowersi & 1 & $1(100 \cdot 0)$ \\
Mus caroli & 7 & 0 \\
Mus cervicolor & 7 & 0 \\
Mus cookii & 27 & 0 \\
Mus sp. & 9 & 0 \\
Rattus exulans & 63 & 0 \\
Rattus tanezumi & 36 & $1(2 \cdot 8)$ \\
Total & 225 & $10(4 \cdot 4)$ \\
\hline \hline
\end{tabular}

Table 2. Comparison of models used to test the effect of several independent variables on individual rodent infection (GLM with logit function)

\begin{tabular}{clc}
\hline \hline Initial model & Model ranks & AIC \\
\hline Rodent & Dist Forest + Dist Settl & $80 \cdot 1$ \\
model 1 & Dist Forest + Dist Agri steep + Dist & $81 \cdot 9$ \\
& Settl & \\
& Dist Forest + Dist Agri steep + Dist & $83 \cdot 7$ \\
& Agri flat + Dist Settl & \\
& & \\
Rodent & Agri steep + Patch & $75 \cdot 1$ \\
model 2 & Agri steep + Forest + Patch & $75 \cdot 9$ \\
& Agri steep + Forest + Settl + Patch & $76 \cdot 7$ \\
& Slope + Agri steep + Forest + Settl + & $78 \cdot 6$ \\
& Patch & $80 \cdot 6$ \\
& Slope + Agri flat + Agri steep + & \\
& Forest + Settl + Patch \\
\hline
\end{tabular}

Models are ranked from the least to the most supported according to corrected Akaike's Information Criterion (AIC). Two initial models were tested: rodent model 1 included the following explanatory variables: slope (Slope), distance from forest (Dist Forest), distance from human settlement (Dist Settl), distance from agriculture on steep land (Dist Agri steep), distance from agriculture on flat land (Dist Agri flat). Rodent model 2 included the following explanatory variables: cover of agriculture on steep land (Agri steep), cover of agriculture on flat land (Agri flat), cover of forest (Forest), cover of human settlement (Settl), patch density (Patch).

area to human cases illustrate those links (Fig. $4 e, f$ ). Moreover, also retained in the best model (lower AIC value), population size appeared not to be statistically associated with human incidence after 2006 (Table 5, Fig. 4d). 
Table 3. Results of the best GLM (with logit link function) of Table 2 explaining the presence of Leptospira species in rodents as a function of habitat characteristics obtained from land cover layers

\begin{tabular}{lllll}
\hline \hline Initial model & Explanatory variables & Estimate (S.D.), $P$ & LR $\chi^{2}, P$ & Residual deviance (D.F.) \\
\hline Rodent model 1 & Dist Forest & $-0 \cdot 016(0 \cdot 009), 0 \cdot 07$ & $5 \cdot 77,0 \cdot 016$ & \\
& Dist Settl & $-0 \cdot 007(0 \cdot 006), 0 \cdot 20$ & $3 \cdot 69,0 \cdot 054$ & $74 \cdot 1(222)$ \\
\multirow{2}{*}{ Rodent model 2 } & Forest & $7 \cdot 89(3 \cdot 32), 0 \cdot 045$ & $5 \cdot 77,0 \cdot 016$ & \\
& Patch & $7 \cdot 38(2 \cdot 64), 0 \cdot 005$ & $512 \cdot 26,0 \cdot 0005$ & $69 \cdot 1(222)$ \\
\hline \hline
\end{tabular}

The initial rodent model 1 included the following explanatory variables: distance from forest (Dist Forest) and distance from human settlement (Dist Settl). The initial rodent model 2 included the following explanatory variables: cover of agriculture on steep (Agri steep), land cover of agriculture on flat land (Agri flat), cover of forest (Forest), cover of human settlement (Settl), patch density (Patch). Values of factors were obtained from the land covers. Explanatory variables were ranked according to their contribution to the model. [LR $\chi^{2}=$ likelihood ratio $\chi^{2}$ test for test of fit for explanatory variable; residual deviance with degrees of freedom (D.F.); global fit given by Wald test.]
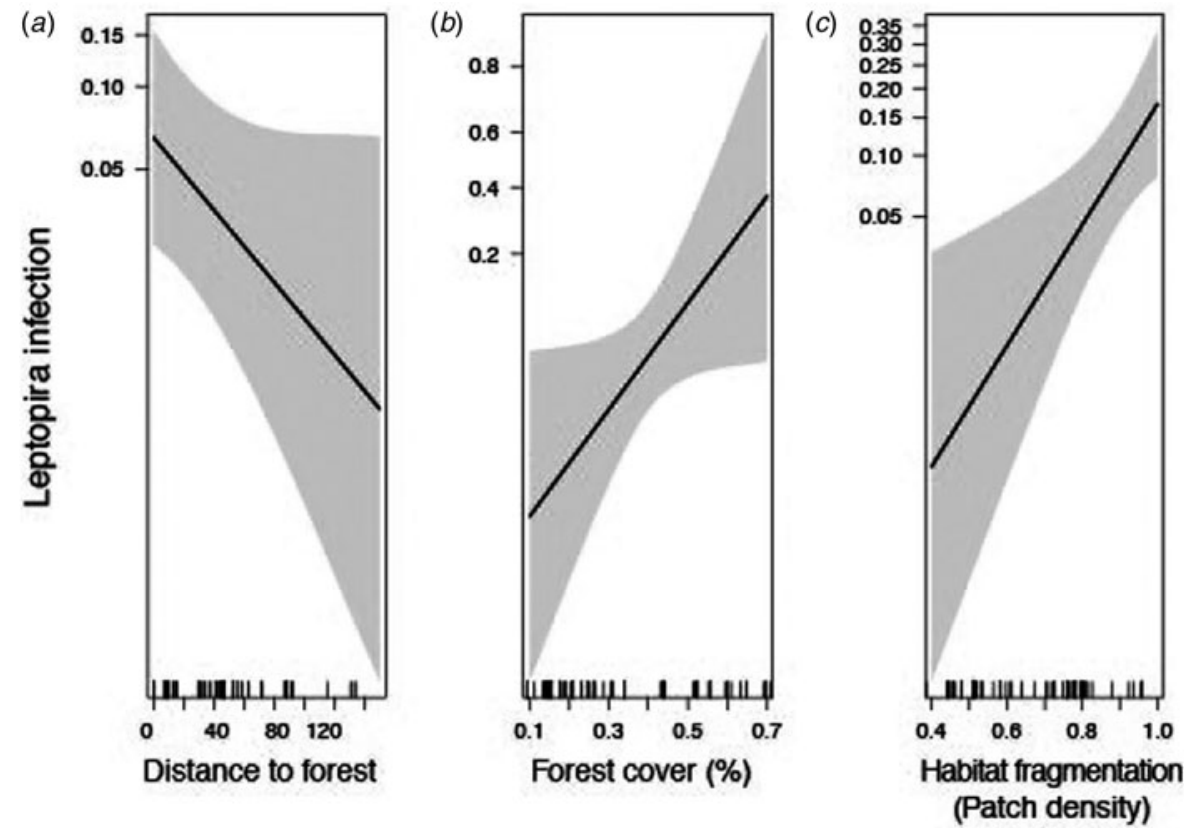

Fig. 3. Partial contribution of $(a)$ distance to the forest, $(b)$ forest cover (in \%) and (c) habitat fragmentation (patch density) in explaining Leptospira infection in rodents from GLM (see selected rodent models in Table 3).

\section{Human incidence during the rodent trapping session (2008-2009)}

To compare environmental factors between rodent infection and human incidence, human model 4 analysed human incidence restricted to the rodent trapping session (2008-2009). The model showed no differences with the previous human models 2 and 3. Increased human cases were found associated with low habitat patchiness and close distance to the river, whereas rodents were likely infected in fragmented habitats comprising large patches of forest and low human settlement cover (Table 5).

\section{Control for spatial autocorrelation}

We detected a strong spatial autocorrelation for human leptospirosis incidence in 2003-2012 (Moran's $I$ statistic, S.D. $=7 \cdot 48, P<0 \cdot 0001)$, population size (Moran's $I$ statistic, S.D. $=3 \cdot 13, P=0 \cdot 0009$ ), and for altitude of village (Moran's $I$ statistics.D. $=14 \cdot 53$, $P<0 \cdot 0001)$. These values suggested strong spatial correlation between all these variables. However, the residual values of the GLM model with the binomial distribution function explaining disease incidence in humans for human model 1 (2003-2012) (see above, Table 5) showed no spatial autocorrelation (Moran's 
Table 4. Comparison of models used to test the effect of several independent variables on leptospirosis incidence in villages of Tha Wang Pha and Pua districts (Nan province, Thailand) using GLM with negative binomial function

\begin{tabular}{|c|c|c|}
\hline Initial model & Model ranks & AIC \\
\hline \multirow[t]{4}{*}{ Human model 1 (2003-2012) } & Pop + Alt + Dist riv + Agri steep + Patch & $558 \cdot 9$ \\
\hline & Pop + Alt + Dist riv + Agri steep + Forest + Patch & $560 \cdot 8$ \\
\hline & Pop + Alt + Dist riv + Agri flat + Agri steep + Forest + Patch & $561 \cdot 6$ \\
\hline & Pop + Alt + Dist riv + Agri flat + Agri steep + Forest + Settl + Patch & $561 \cdot 6$ \\
\hline \multirow[t]{4}{*}{ Human model 2 (2003-2006) } & Pop + Alt + Dist riv + Agri steep + Patch & $410 \cdot 8$ \\
\hline & Pop + Alt + Dist riv + Agri flat + Agri steep + Patch & $411 \cdot 2$ \\
\hline & Pop + Alt + Dist riv + Agri flat + Agri steep + Forest + Patch & $413 \cdot 2$ \\
\hline & Pop + Alt + Dist riv + Agri flat + Agri steep + Forest + Settl + Patch & $413 \cdot 2$ \\
\hline \multirow[t]{4}{*}{ Human model 3 (2007-2012) } & Pop + Dist riv + Agri flat + Agri steep + Forest & $398 \cdot 8$ \\
\hline & Pop + Dist riv + Agri flat + Agri steep + Forest + Patch & $400 \cdot 2$ \\
\hline & Pop + Alt + Dist riv + Agri flat + Agri steep + Forest + Patch & $401 \cdot 9$ \\
\hline & Pop + Alt + Dist riv + Agri flat + Agri steep + Forest + Settl + Patch & $401 \cdot 9$ \\
\hline \multirow[t]{4}{*}{ Human model 4 (2008-2009) } & Pop + Alt + Dist riv + Agri flat + Patch & $261 \cdot 8$ \\
\hline & Pop + Alt + Dist riv + Agri flat + Forest + Patch & $262 \cdot 0$ \\
\hline & Pop + Alt + Dist riv + Agri flat + Forest + Settl + Patch & $262 \cdot 6$ \\
\hline & Pop + Alt + Dist riv + Agri flat + Agri steep + Forest + Settl + Patch & $264 \cdot 3$ \\
\hline
\end{tabular}

Models are ranked from the least to the most supported according to corrected Akaike's Information Criterion (AIC). Four initial models were tested: human model 1 (2003-201); human model 2 (2003-2006); human model 3 (2007-20012); human model 4 (2008-2009). Each model included the following explanatory variables: population size (Pop), altitude (Alt), distance from river (Dist riv), cover of agriculture on steep land (Agri steep), cover of agriculture on flat land (Agri flat), cover of forest (Forest), cover of human settlement (Settl) and patch density (Patch).

$I$ statistic, s.D. $=0 \cdot 30, P=0 \cdot 38)$. Similar lack of spatial autocorrelation of residuals was observed for human models $2-4$.

\section{DISCUSSION}

\section{Rodent infection and habitat}

The results presented here for the two districts of Nan province are similar to those obtained in the analyses performed on rodents from seven different sites in Thailand, Cambodia and Lao PDR [6]. Similar to the study of Cosson et al. [6], although restricted to these two districts of Nan province, we found that the rodents carrying Leptospira were those trapped in forests or in patchy environment mostly located on hills.

An analysis of agrarian systems was made in one village of Tha Wang Pha district (P. Belchi, unpublished data), which appears fairly representative of the villages affected by the 2006 outbreak and also of a rapid shift in crop cultivation. Maize and rice are the main crops cultivated. Rice is grown and consumed mostly locally, whereas maize is a cash crop that has increased significantly over the last 10 years fostered by a strong public sector investment in research and extension, maize production being promoted by the Ministry of Agriculture particularly for the production of input for livestock producers and feed millers [32]. Indeed, Northern Thailand has become the leading producer of corn in the country, with a contribution of $49 \%$ to the national production [33]. The spread of this new culture has profoundly impacted the agricultural landscape. Maize is cultivated under rain-fed conditions on hill land where the soil surface devoted to cultivation is insufficiently watered, even during the rainy season, due to the steepness of the slope. Farmers recognized strong erosion problems associated with significant decline in soil fertility. They noted that the expansion of the cultivation of corn was associated with a significant increase in the number of rats on this agricultural land. A rodent outbreak was noticed in 2008, which particularly affected some cornfields.

\section{Human incidence and habitat}

Since the floods of 2006, the authorities have implememted regular awareness campaigns on prevention of leptospirosis (and measures of prophylaxis such as 
Table 5. Results of the best GLM (with negative binomial function) of Table 4 explaining the leptospirosis incidence in the villages of Tha Wang Pha and Pua districts (Nan province, Thailand) as a function of habitat characteristics obtained from land cover layers

\begin{tabular}{|c|c|c|c|c|c|}
\hline Initial model & $\begin{array}{l}\text { Explanatory } \\
\text { variables }\end{array}$ & Estimate (S.D.), $P$ & $\operatorname{LR} \chi^{2}, P$ & $\begin{array}{l}\text { Theta } \\
\text { (s.D.) }\end{array}$ & $\begin{array}{l}\text { Residual deviance } \\
\text { (D.F.) }\end{array}$ \\
\hline $\begin{array}{l}\text { Human model } 1 \text { (2003- } \\
\text { 2012) }\end{array}$ & $\begin{array}{l}\text { Patch } \\
\text { Dist Riv } \\
\text { Agri steep } \\
\text { Pop } \\
\text { Alt }\end{array}$ & $\begin{array}{c}-77 \cdot 8(19 \cdot 6),<0 \cdot 0001 \\
-33 \cdot 5(7 \cdot 5),<0 \cdot 0001 \\
3 \cdot 7(1 \cdot 1), 0 \cdot 0009 \\
0 \cdot 0006(0 \cdot 003), 0 \cdot 05 \\
-0 \cdot 007(0 \cdot 006), 0 \cdot 20\end{array}$ & $\begin{array}{c}14 \cdot 37,<0 \cdot 0001 \\
13 \cdot 79,<0 \cdot 0001 \\
9 \cdot 99,0 \cdot 002 \\
3 \cdot 51,0 \cdot 06 \\
2 \cdot 79,0 \cdot 09\end{array}$ & $2 \cdot 44(0 \cdot 72)$ & $180 \cdot 1(161)$ \\
\hline $\begin{array}{l}\text { Human model } 2 \text { (2003- } \\
\text { 2006) }\end{array}$ & $\begin{array}{l}\text { Dist Riv } \\
\text { Alt } \\
\text { Pop } \\
\text { Agri steep } \\
\text { Patch }\end{array}$ & $\begin{array}{l}-28 \cdot 4(10 \cdot 9), 0 \cdot 009 \\
-0 \cdot 11(0 \cdot 004), 0 \cdot 012 \\
0 \cdot 0009(0 \cdot 004), 0 \cdot 019 \\
3 \cdot 2(1 \cdot 5), 0 \cdot 028 \\
-41 \cdot 4(25 \cdot 4), 0 \cdot 10\end{array}$ & $\begin{array}{l}7 \cdot 40,0 \cdot 007 \\
6 \cdot 95,0 \cdot 008 \\
5 \cdot 63,0 \cdot 018 \\
4 \cdot 67,0 \cdot 031 \\
2 \cdot 51,0 \cdot 11\end{array}$ & $2 \cdot 13(0 \cdot 81)$ & $157 \cdot 7(161)$ \\
\hline $\begin{array}{l}\text { Human model } 3 \text { (2007- } \\
\text { 2012) }\end{array}$ & $\begin{array}{l}\text { Dist Riv } \\
\text { Forest } \\
\text { Agri steep } \\
\text { Agri flat } \\
\text { Pop }\end{array}$ & $\begin{array}{c}-36 \cdot 6(8 \cdot 1),<0 \cdot 0001 \\
7 \cdot 9(2 \cdot 4), 0 \cdot 0009 \\
11 \cdot 0(3 \cdot 2), 0 \cdot 0007 \\
6 \cdot 5(2 \cdot 7), 0 \cdot 016 \\
0 \cdot 0006(0 \cdot 0004), 0 \cdot 11\end{array}$ & $\begin{array}{c}27 \cdot 49,<0 \cdot 0001 \\
11 \cdot 72,0 \cdot 0006 \\
11 \cdot 51,0 \cdot 0007 \\
6 \cdot 32,0 \cdot 012 \\
2 \cdot 39,0 \cdot 12\end{array}$ & $1 \cdot 81(0 \cdot 74)$ & $157 \cdot 2(161)$ \\
\hline $\begin{array}{l}\text { Human model } 4 \text { (2008- } \\
\text { 2009) }\end{array}$ & $\begin{array}{l}\text { Patch } \\
\text { Alt } \\
\text { Dist Riv } \\
\text { Pop } \\
\text { Agri flat }\end{array}$ & $\begin{array}{c}-0 \cdot 77(0 \cdot 31), 0 \cdot 014 \\
-0 \cdot 010(0 \cdot 005), 0 \cdot 11 \\
-0 \cdot 21(0 \cdot 17), 0 \cdot 061 \\
0 \cdot 0008(0 \cdot 0005), 0 \cdot 12 \\
-0 \cdot 14(0 \cdot 09), 0 \cdot 14\end{array}$ & $\begin{array}{l}6 \cdot 2,0 \cdot 01 \\
3 \cdot 86,0 \cdot 049 \\
3 \cdot 62,0 \cdot 050 \\
2 \cdot 50,0 \cdot 11 \\
2 \cdot 33,0 \cdot 13\end{array}$ & $2.07(1.66)$ & $126 \cdot 2(161)$ \\
\hline
\end{tabular}

Four initial models were tested: human model 1 (2003-2012); human model 2 (2003-2006); human model 3 (2007-20012); human model 4 (2008-2009). Each model included the following explanatory variables: population size (Pop), altitude (Alt), distance from river (Dist riv), cover of agriculture on steep land (Agri steep), cover of agriculture on flat land (Agri flat), cover of forest (Forest), cover of human settlement (Settl) and patch density (Patch). Explanatory variables were ranked according to their contribution to the model. [Theta and S.D. of the negative binomial distribution; LR $\chi^{2}=$ likelihood ratio $\chi^{2}$ test for test of fit for explanatory variable; residual deviance with degrees of freedom (D.F.); global fit given by Wald test.]

free antibiotic distribution). The results of the GLM analyses showed that, before and after 2006, the dynamics of leptospirosis seemed to change significantly. For example, during the flooding of 2011 there were threefold fewer cases than during the flooding of 2006. After 2006, the human infection appears more strongly linked to land use, obviously dependent on land management options. Based on the results from 2003 to 2006, the human incidence was correlated with a short distance to the river, which is in accord with the increase of cases during the flooding of 2006. After 2006, the correlated variables were more related to land use with no influence of human population size. This result confirms the significant and positive effects of the provincial public health on the incidence of the diseases in these two districts of Nan province.

The observation that population size did not further correlate with human incidence after 2006 suggests that public health campaigns have improved the knowledge, attitudes and practices of the population toward leptospirosis. Hence, a study based on individual interviews conducted in a village of Tha Wang Pha district in 2013 [34], confirmed the population's awareness regarding leptospirosis infection and prevention. A better diagnosing and reporting of the disease may have occurred after 2006 with a population better informed about symptoms, and health officers more aware than before. The level of human incidence after 2006 is likely to be explained by risky behaviours and lack of prevention by infected people.

\section{Humans and rodents were not infected in similar habitats}

Although the dynamics of the disease has changed over the past decade, the rodent infection showed 
(a)

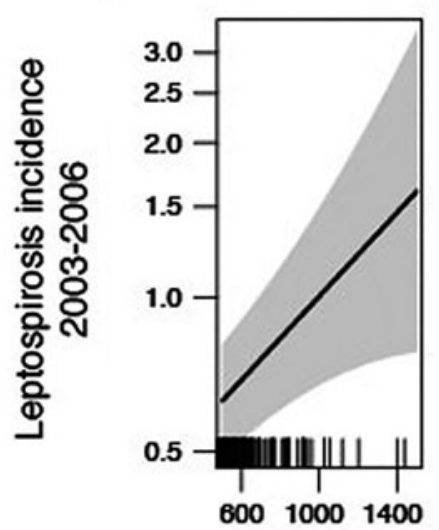

Population size

(d)

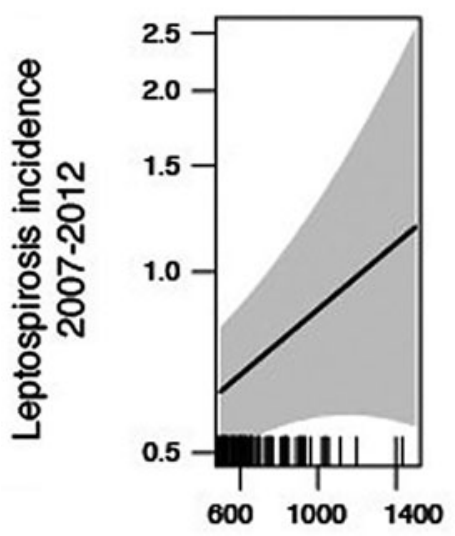

Population size (b)

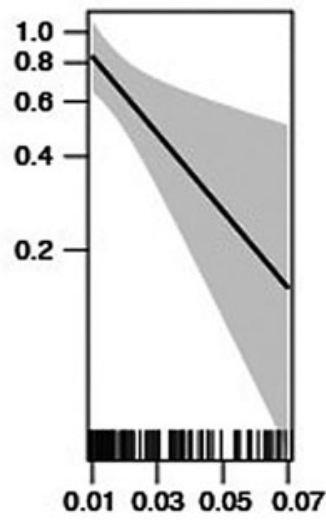

Distance to river

(e)

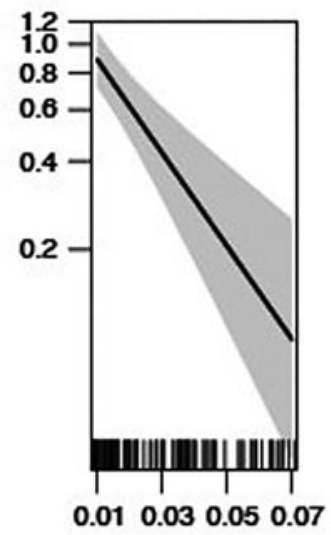

Distance to river (c)

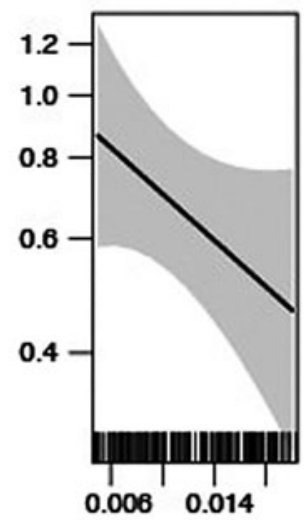

Habitat fragmentation (Patch density)

$(f)$

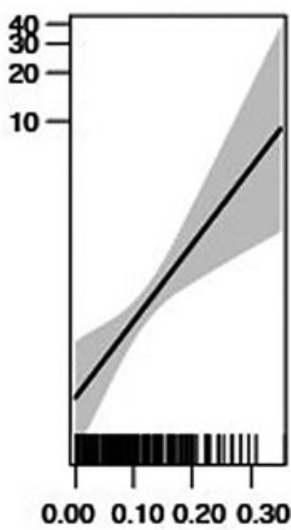

Agriculture on slope

(\%)

Fig. 4. Partial contribution of $(a)$ population size, $(b)$ distance to river and (c) habitat fragmentation (patch density) in explaining leptospirosis infection in Tha Wang Pha and Pua districts in 2003-2006 from GLM (selected human model 2 in Table 5). Partial contribution of $(d)$ population size, $(e)$ distance to river and $(f)$ cover of agriculture in slope (in \%) in explaining leptospirosis infection in Tha Wang Pha and Pua districts in 2007-2012 from GLM (selected human model 3 in Table 5).

different environmental patterns than human infection when investigating the period 2008-2009. Leptospirosis in rats correlated with a significant proportion of forest in a patchy landscape principally situated on hills, whereas human infections occurred in villages in non-forested and non-patchy areas located in the vicinity of rivers. The water factor, i.e. distance to river or the potential of flooding, was investigated for human and rodent infection, but appeared related only to human infection. The water factor, as depicted as distance to river, seems to have a greater influence on human infection than on rodent infection.
These results challenge the role of rodents as carriers or reservoirs of Leptospira. Moreover, the overall decrease of livestock, either cattle or buffaloes, linked to the increase of agricultural intensification and productivity also questions their roles in the transmission of the disease.

Finally, the statistical observation that humans and rodents are infected in different habitats/environments, at least for the period investigated in this study, urges us to improve our knowledge on the microbial ecology of the bacteria. Indeed, few studies have investigated the requirements of the free-living 
bacteria in the soil or the role of the virulence factors in its survival and growth [22, 35, 36]. Further studies should collect environmental samples in order to collect and grow environmental leptospires. Our study may help in targeting habitats for sampling.

\section{Limits and implications of the study}

One can question the choice of variables in relation to these different time scales as the human epidemiological data covered the years 2003-2012, while the variables concerning the rodent infection and land use were related to 2007-2008. In a context of rapidly changing land use as observed in Nan province, this may have potentially biased the analyses concerning the data prior to 2006 even if the land cover has been simplified in order to reduce the potential biases linked to land-use changes. During the period of the propagation of corn culture, farmers in Nan province encroached on the lands of forest reserves to the detriment of the forested areas resulting in rapid land-use changes and the deterioration of water catchments due to a massive use of pesticides to increase maize production (encouraged by the implementation of a governmental natural disaster risk insurance scheme for maize from 2007).

In order to limit the encroachment of agriculture in forested areas, the government implemented an agrarian reform, leading to the regulation of land by granting property titles, thus limiting the expansion of agricultural land into the forest [32].

Nowadays, agricultural parcels have little chance of returning to a forest plot in a context where the pressure on agricultural land is still strong. However, shifts to rubber plantations were also observed due to the provision of subsidies to local farmers of the province (from 2005 ) as an incentive to grow rubber. In addition, as stated by Suzuki [37], financial incentives such as REDD+ could benefit climate change mitigation and adaptation and at the same time, provide support for the communities to manage the forests sustainably. In 'utilization forest' zones where some activities such as farming are possible, it has been noted that community management could lead to natural regeneration and biodiversity similar to 'conservation' forests, where human activity is forbidden [38]. It might go alongside community watershed management and restoration. However, from 2007 the slight increase of forest land area (National Statistical Office of Thailand, 2013) could be explained by the existence and promotion of community forest management, an area of forest managed by the local community. Even though community forest management has been practised for more than 100 years by Thai people [39], it was not legally framed [40].

The overlapping systems of management of natural resources associated with water or forest community management, agricultural practices, dam projects, and flood management are leading to natural-resource and land-use changes. For instance, deforestation for agricultural purposes resulted in an increased run-off coefficient [41]. This dynamics of change should be studied further as it affects the risk of leptospirosis, particularly in a context of climate change. If the environment is influenced first by physical factors it is also a result of policies and regulations in various sectors such as forest conservation, water resource management, agricultural policies and rural property law. Ultimately, environmental changes are linked with political and economic choices which may contribute to the changes regarding the risk of leptospirosis [26].

\section{ACKNOWLEDGEMENTS}

This study was funded by the French ANR Biodiversity, grant ANR 07 BDIV 012 CERoPath project ('Community Ecology of Rodents and their Pathogens in a changing environment') (www.ceropath.org), and by the French ANR CP\&ES, grant ANR 11 CPEL 002 BiodivHealthSEA project ('Local impacts and perceptions of global changes: Biodiversity, health and zoonoses in Southeast Asia') (www.biodivhealthsea.org). SPOT images and SPOT DEMs were obtained with financial support of the ISIS ('Incitation à l'utilisation Scientifique des Images SPOT') programme operated by the French Space Agency, CNES (Centre National d'Etudes Spatiales). The authors thank S. Dupuy, CIRAD, for image processing, and special thanks to all participants in the fieldwork for their great help. We also thank two anonymous reviewers for helpful comments.

\section{DECLARATION OF INTEREST}

None.

\section{REFERENCES}

1. Bharti AR, et al. Leptospirosis: a zoonotic disease of global importance. Lancet Infectious Diseases 2003; 3: 757-771. 
2. Pappas G, et al. The globalization of leptospirosis: worldwide incidence trends. International Journal of Infectious Diseases 2008; 12: 351-357.

3. Hartskeerl RA, Collares-Pereira M, Ellis WA. Emergence, control and re-emerging leptospirosis: dynamics of infection in the changing world. Clinical Microbiology and Infection 2011; 17: 494-501.

4. Perez J, et al. Rodent abundance dynamics and Leptospirosis carriage in an area of hyper-endemicity in New Caledonia. PLoS Neglected Tropical Diseases 2011; 5: e1361.

5. Ivanova S, et al. Leptospira and rodents in Cambodia: environmental determinants of infection. American Journal of Tropical Medicine and Hygiene 2012; 86, 1032-1038.

6. Cosson J-F, et al. Epidemiology of Leptospira transmitted by rodents in Southeast Asia. PLoS Neglected Tropical Diseases 2014; 8: e2902.

7. Abela-Ridder B, Sikkema R, Hartskeerl RA. Estimating the burden of human leptospirosis. International Journal of Antimicrobial Agents 2010; 36: S5-7.

8. Ko A, et al. Salvador Leptospirosis Study Group. Urban epidemic of severe leptospirosis in Brazil. Lancet 1999; 354: 820-825.

9. Laras K, et al. 2002: The importance of leptospirosis in Southeast Asia. American Journal of Tropical Medicine and Hygiene 67, 278-286.

10. Berlioz-Arthaud A, et al. Hospital-based active surveillance of human leptospirosis in Cambodia. Bulletin de la Société de Patholologie Exotique 2010; 103: 111-118.

11. Thaipadungpanit $\mathbf{J}$, et al. A dominant clone of Leptospira interrogans associated with an outbreak of human leptospirosis in Thailand. PLoS Neglected Tropical Diseases 2007; 1: e56.

12. Kawaguchi L, et al. Seroprevalence of leptospirosis and risk factor analysis in floodprone rural areas in Lao PDR. American Journal of Tropical Medicine and Hygiene 2008; 78: 957-996.

13. Amilasan AT, et al. Outbreak of leptospirosis after flood, the Philippines, 2009. Emerging Infectious Diseases 2012; 18: 91-94.

14. Victoriano AF, et al. Leptospirosis in the Asia Pacific region. BMC Infectious Diseases 2009; 9: 147.

15. Desvars A, Cardinale E, Michault A. Animal leptospirosis in small tropical areas. Epidemiology and Infection 2011; 139: 167-188.

16. Wangroongsar $\mathbf{P}$, et al. Survey of leptospirosis among rodents in epidemic areas of Thailand. Journal of Tropical Medicine and Parasitology 2002; 25: 55-58.

17. de Faria MT, et al. Carriage of Leptospira interrogans among domestic rats from an urban setting highly endemic for leptospirosis in Brazil. Acta Tropica 2008; 108: $1-5$.

18. Meerburg BG, Singleton GR, Kijlstra A. Rodent-borne diseases and their risks for public health. Critical Review in Microbiology 2009; 35: 221-270.

19. Agudelo-Florez P, et al. Prevalence of Leptospira spp. in urban rodents from a groceries trade center of Medellin, Colombia. American Journal of Tropical Medicine and Hygiene 2009; 81: 906-910.
20. Benacer D, et al. Isolation and molecular characterization of Leptospira interrogans and Leptospira borgpetersenii isolates from the urban rat populations of Kuala Lumpur, Malaysia. American Journal of Tropical Medicine and Hygiene 2013; 88: 704-709.

21. Trueba G, et al. Cell agregation: a mechanism of pathogenic Leptospira to survive in fresh water. International Microbiology 2004; 7: 35-40.

22. Ganoza CA, et al. Determining risk for severe leptospirosis by molecular analysis of environmental surface waters for pathogenic Leptospira. PLoS Medicine 2006; 3: e308.

23. Tangkanakul W, et al. Leptospirosis: an emerging health problem in Thailand. Southeast Asia Journal Tropical Medicine and Public Health 2005; 36: 281-288.

24. Wuthiekanun V, et al. Clinical diagnosis and geographic distribution of leptospirosis, Thailand. Emerging Infectious Diseases 2007; 13: 124-126.

25. Dupuy S, et al. Land cover dynamics in Southeast Asia: contribution of object-oriented techniques for change detection. Geobia Proceedings of the 4th Geobia, 7-9 May 2012, Rio de Janeiro, Brazil, pp. 217-222.

26. Morand S, et al. Assessing the distribution of diseasebearing rodents in human-modified tropical landscapes. Journal of Applied Ecology 2015; 52: 784-794.

27. Kurilung A, et al. Detection and isolation of Leptospira sp. in domestic animals, Nan Province, Thailand. Proceedings of the 14th Chulalongkorn University Veterinary Conference, Responsible for Lives, 2015. Bangkok, Thailand

28. Herbreteau V, et al. Field and Laboratory Protocols for Rodent Studies. Kasetsart University Press, 2011, Thailand, Bangkok.

29. Bordes F, et al. The diversity of microparasites of rodents: a comparative analysis that helps in identifying rodent-borne rich habitats in Southeast Asia. Infection Ecology and Epidemiology 2013; 3: 20178.

30. Galan M, Pagès M, Cosson J-F. Next-generation sequencing for rodent barcoding: species identification from fresh, degraded and environmental samples. PLOS ONE 2012; 7: e4837.

31. R Core Team. R: A language and environment for statistical computing. R Foundation for Statistical Computing, 2015, Vienna, Austria (http://www.R-project.org/).

32. Ekasingh B, Thong-Ngam K. Thailand: Maize economy, incentives and policies. In: Gulati A, Dixon JM, eds. Maize in Asia, Changing Markets and Incentives. Academic Foundation, India, New Delhi, 2008.

33. Ekasingh B, et al. Maize in Thailand: production systems, constraints, and research priorities. Mexico: International Maize and Wheat Improvement Center (CIMMYT), 2004, Mexico.

34. Della Rossa P. Contribution of a quantitative and qualitative study of environmental factors to the understanding of leptospirosis dynamics, in a north district of Thailand (unpublished Master's thesis), College of International Agro-Development, 2013, France.

35. Picardeau M, et al. 2008: Genome sequence of the saprophyte Leptospira biflexa provides insights into 
the evolution of Leptospira and the pathogenesis of leptospirosis. PloS ONE 2008; 3: e1607.

36. Aviat F, et al. Leptospira exposure in the human environment in France: a survey in feral rodents and in fresh water. Comparative Immunology Microbiology and Infectious Diseases 2009; 32: 463-476.

37. Suzuki R. Linking adaptation and mitigation through community forestry: Case studies from Asia, RECOFTC. The Center for People and Forests, Thailand, 2012, Bangkok.

38. Kijtewachakul N, Shivakoti GP, Webb EL. Forest health, collective behaviors, and management. Environment and Management 2004; 33: 620-636.
39. Salam A, et al. Community forest management in Thailand: current situation and dynamics in the context of sustainable development. New Forests 2006; 31: 273-291.

40. Lubanski J. Land is life: a policy advocacy case study of the Northern Thailand land reform movement. SIT Graduate Institute, Capstone Collection, 2012, Paper 2565 (http://digitalcollections.sit.edu/capstones/2565).

41. Pakoksung K, Koontanakulvong S. The effect of landuse change on runoff in the Nan basin. Society for Social Management Systems Internet Journal 2011. Japanese Institutional Repositories Online (http:// kutarr.lib.kochi-tech.ac.jp/dspace/bitstream/10173/860/1/ sms11-8256.pdf). 